\title{
AGE-RELATED DIFFERENCES IN COMMON SANDPIPER TRINGA GYPOLEUCOS (LINNAEUS) FORAGING AND AGGRESSIVE BEHAVIOUR IN OPA RESERVOIR, ILE-IFE, NIGERIA
}

\author{
A.X. AKINPELU ${ }^{+}$and M.E. FAJEMILEHIN \\ Department of Zoology, Obafemi Awolowo University, Ile-Ife, Nigeria.
}

(Submitted: 09 August 2004; Accepted: 31 October 2004)

\begin{abstract}
Foraging behaviour of common Sandpiper was studied on the low water level and sand and weed-littered banks of Opa reservoir on the campus of Obafemi Awolowo University, Ile-Ife. Foraging rates differed significantly between the two areas. In each of the two areas the foraging and success rates of adults and juveniles differed significantly while the frequencies of success were similar for both age groups. Experience in searching for and handling of prey may be a primary factor responsible for the observed differences in foraging rates of adults and juveniles. These rates may improve with maturity and experience.

Adults and juveniles in the tail-depressed posture were dominant in aggressive interactions than birds in the tail-level posture. In mixed flocks of foraging sandpipers, four possible types of aggressive interactions occurred. Adult over juvenile interactions occurred more frequently than expected, and juvenile over adult interactions were never observed.
\end{abstract}

Keywords: Sandpiper, age, foraging, postures, aggression.

\section{Introduction}

Mortality in young birds than in adults is common and widespread in avian species (Lack, 1954; Akinpelu, 2001). This simply suggests that juveniles are rather more inept than adults in coping with the rigors of survival (Orians, 1969). A variety of behavioural, social and genetic factors may account for such differences.

Although Lack (1966) suggested that food supply is a major factor in density-dependent regulation, Ashmole (1963) and Akinpelu (2001) hypothesize that starvation is a major factor in the higher juveniles mortality. Hence young birds are less efficient than adults in foraging. According to Recher and Recher (1969), foraging inefficiency can be attributed to a variety of behavioural differences including acquired proficiency and skill in searching for and handling prey, and those of a social or psychological nature related to aggression, dominance, flocking and other social factors. The extent to which these aspects of behaviour interact to influence foraging efficiency is difficult to determine.

This study was to examine differences, if any, in foraging and social behaviour of conspecific juveniles and adults. The common Sandpiper Tringa hypoleucos were studied on the banks of Opa
Reservoir, Obafemi Awolowo University, Ile-Ife, Nigeria.

\section{Materials and Methods}

The common sandpiper was studied on the banks of Opa reservoir situated on the campus of Obafemi Awolowo University, Ile-Ife. The reservoir (longitudes $4^{\circ} 31^{\prime} \mathrm{E}$ to $4^{\circ} 32^{\prime} \mathrm{E}$ and latitudes $7^{\circ} 29^{\prime} \mathrm{N}$ to $7^{\circ} 30^{\prime} \mathrm{N}$; Fig. 1) has a surface area of $0.95 \mathrm{~km}^{2}$ with a maximum capacity of about $675 \mathrm{~m}^{3}$. A lot of submerged trees are scattered all over the reservoir. A high water discharge is received during the rainy season (April-October) from many streams and rivers within the catchment area so that the water remains turbid because of sediments from highlands and farmlands. During this period the banks are over flooded to the extent that a lot of water is then let out through the auxillary spillway. The shoreline vegetation is dense with plants like Commelina diffusa, C. erecta, Amaranthus hibridus, Acroceras zizanoides and other aquatic macrophytes (Komolafe, 1985). The water recedes during the dry season (November-March) leaving the banks open to the activities of foraging birds. Common sandpipers were watched foraging on different 


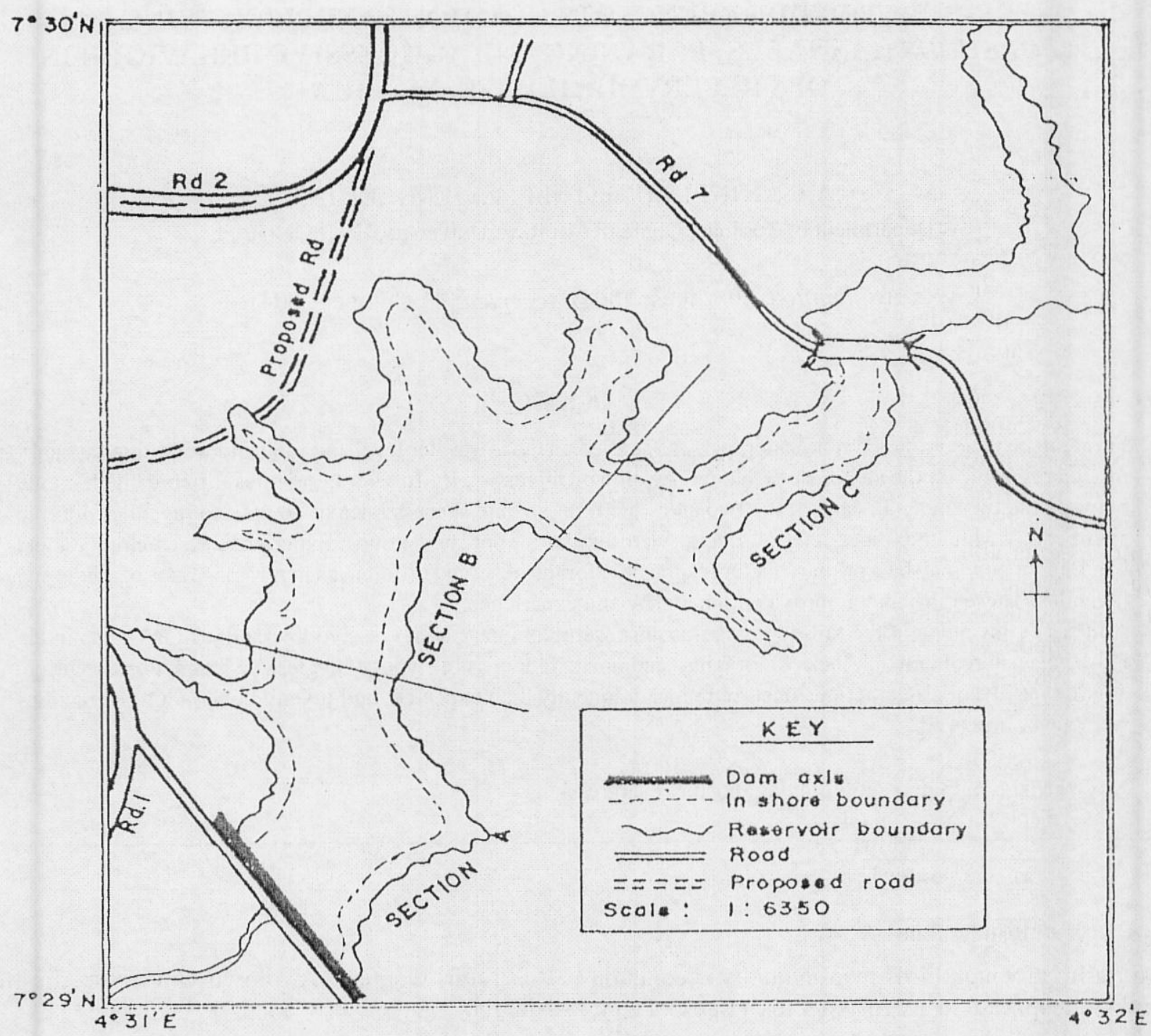

Fig. 1: Opa reservoir (Source: Komolafe, 1985)

substrates including wet sand close to the water line, sand, mud and weed littered flats.

The birds typically appeared and started foraging as early as $06.30 \mathrm{~h}$ on invertebrates like shrimps, crabs, oligochaetes and amphipods attached to decomposed weed-littered banks. The decomposed weeds lasted for about eight weeks and were frequented by foraging sandpipers. Data were gathered on 166 sandpipers (99 adults, 67 juveniles) during nearly daily observation period from 5 August to 25 September, 2003.

Daily observation periods ranged from 30 to 180 minutes. Individual birds were watched for periods of 30 to 1,500 seconds with $8 / 50 \mathrm{~m} / \mathrm{m}$ binoculars and timed to the nearest second with a stopwatch. As soon as the identity of an individual bird became uncertain the observation was ended and a new subject was selected arbitrarily. Each birds age and plumage were noted, the habitat characterized, the number and ages of common sandpipers around the subject noted, and the estimated size of the area occupied by a group of the birds $\left(1-10 \mathrm{~m}^{2}\right)$ recorded. Throughout each observation the birds postural changes were recorded as well as the occurrence and outcome of all interactions with other birds. Up to 20 different birds were watched daily and each timed observation of a bird was treated as a separate case because of the impossibility of identifying individuals positively form day to day.

Two types of foraging techniques were classified and recorded i.e. directed foraging movement involving contact of the birds bill with the substrate or manipulation of substrate in search of food $(F)$ and prey capture and ingestion $(P)$ when the head is raised while making visible swallowing movement. Foraging rate was taken as $\frac{P+F}{t}$, success rate as $\frac{P}{t}$ and frequency of success as $\frac{\mathrm{P}}{(\mathrm{P}+\mathrm{F})}$, where $t$ was time 
in seconds. Results were then analysed by MannWhitney U-test and Chi-square one sample test.

All interactions were identified by the type, age of participants and outcomes of interactions, i.e., adult over adult, adult over juvenile, juvenile over adult and juvenile over juvenile. Ridpath (1972) model on how to predict frequencies of age-related interactions was applied to the data. For a mixed adult and juvenile flock, $P=$ number of adult/number of adults + juveniles; $q=$ number of juveniles/ (number of adults + juveniles) and $(p+q)=1$.

Assuming random occurrence of all types of aggressive interactions $p^{2}+2 p q+q^{2}=1$ predicts the expected frequencies of all types of aggressive interactions where $p^{2}$ represents all adult over adult interactions, $q^{2}$ represents all juvenile over juvenile interactions and $2 p q$ represents all adults over juvenile and juvenile over adult interactions. Directions of deviations from expected frequencies were tallied and evaluated by sign test (Brase and Brase, 1987).

\section{Results}

The birds located prey by directed foraging movements involving flicking up pieces of weed with bill and using the bill to peck or dig in the sand, overturning piles of weed, flipping stones with upward bill movement. Several manipulations of the weed, sand or stones preceded a prey capture. At times active searching and pursuing of mobile crustaceans and worms resulted in a capture and subsequently swallowed.

The birds in the two foraging situations, i.e. low water level banks and sand and weed-littered flats were considered separately because foraging rates in the two situations showed highly significant agedependent differences (Table $1, P<0.001$ MannWhitney U-test). It showed that there were statistically significant differences in the foraging and success rates of adults and juveniles. The timeindependent frequencies of success were closely equivalent.

Table 1: Foraging rates, success rates, frequency of success of common Sandpipers on two substrates.

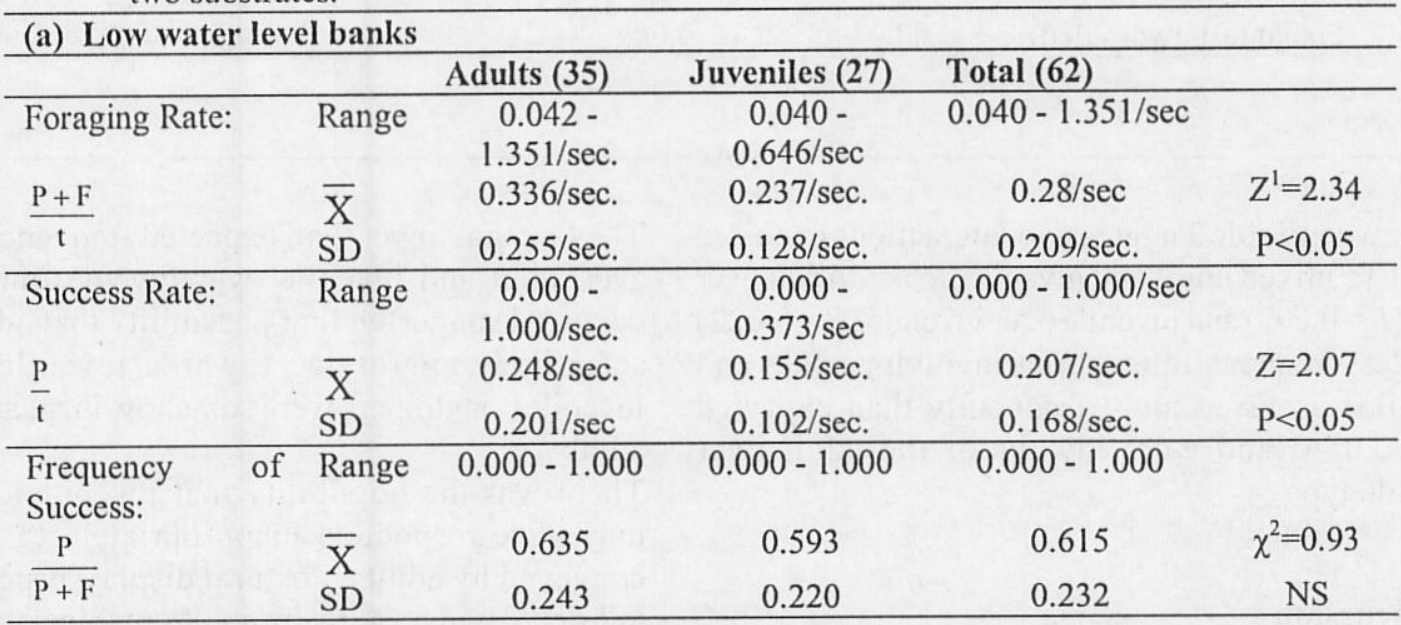

(b) Sand and weed littered banks

\begin{tabular}{|c|c|c|c|c|c|}
\hline & & Adults (35) & Juveniles (27) & Total (62) & \\
\hline \multirow[t]{2}{*}{ Foraging Rate: } & Range & $0.055-$ & 0.012 - & 0.012 - & \\
\hline & & $0.534 / \mathrm{sec}$ & $0.353 / \mathrm{sec}$ & $0.534 / \mathrm{sec}$ & \\
\hline \multirow{2}{*}{$\frac{P+F}{t}$} & $\bar{X}$ & $0.211 / \mathrm{sec}$ & $0.177 / \mathrm{sec}$ & $0.195 / \mathrm{sec}$ & $Z^{1}=3.39$ \\
\hline & SD & $0.069 / \mathrm{sec}$ & $0.068 / \mathrm{sec}$. & $0.069 / \mathrm{sec}$ & $\mathrm{P}<0.01$ \\
\hline Success Rate: & Range & $\begin{array}{c}0.041- \\
0.460 / \mathrm{sec}\end{array}$ & $\begin{array}{c}0.000- \\
0.352 / \mathrm{sec} .\end{array}$ & $0.000-4.60 / \mathrm{sec}$ & \\
\hline \multirow{2}{*}{$\frac{P}{t}$} & $\bar{X}$ & $0.173 / \mathrm{sec}$. & $0.142 / \mathrm{sec}$. & $0.160 / \mathrm{sec}$. & $Z=3.12$ \\
\hline & SD & $0.068 / \mathrm{sec}$ & $0.068 / \mathrm{sec}$ & $0.069 / \mathrm{sec}$. & $\mathrm{P}<0.01$ \\
\hline \multirow{3}{*}{$\begin{array}{l}\text { Frequency } \\
\text { Success: } \\
\frac{P}{P+F}\end{array}$} & of Range & $0.261-1.000$ & $0.000-1.000$ & $0.000-1.000$ & \\
\hline & $\bar{X}$ & 0.785 & 0.783 & 0.784 & $\chi^{2}=0.10$ \\
\hline & SD & 0.108 & 0.167 & 0.135 & NS \\
\hline
\end{tabular}


Tail level posture with the head held upright, wings against the body, the tail held in line with the body axis, contour feathers smooth and flat formed the first of the two postures commonly observed in the common sandpipers. The tail depressed posture, where the tail is depressed below the body axis, was frequently associated with chasing and aggression, and sometimes accompanied by head lowering and raised scapulars (hunched appearance).
Table 2 shows the postures and dominance in aggressive interactions. Those in the tail-depressed posture were dominant in aggressive interactions much more often than those in the tail-level posture $\left(\chi^{2}=13.81, P<0.001\right)$. No age-related differences in the frequency with which adults and juveniles in the two postures were dominant in aggressive interactions were noted.

Table 2: Posture and dominance in aggressive interactions among $143 \mathrm{common}$ Sandpipers

\begin{tabular}{cccc}
\hline Posture & Age & $\begin{array}{c}\text { Number of birds } \\
\text { observed in posture }\end{array}$ & $\begin{array}{c}\text { Number of birds dominant } \\
\text { in aggressive interaction }\end{array}$ \\
\hline Tail-level & Adult & 24 & 1 \\
Tail-depressed & Juvenile & 11 & 1 \\
& Adult & 33 & 15 \\
& Juvenile & 25 & 9 \\
\hline
\end{tabular}

Table 3: Comparison of observed and expected frequency of dominance in aggressive interactions in 8 mixed-age flocks of common Sandpipers.

\begin{tabular}{lcccc}
\hline & $\mathrm{p}^{2}$ & $2 \mathrm{pq}$ & & $\mathrm{q}^{2}$ \\
\cline { 2 - 5 } & $\begin{array}{c}\text { Adult over } \\
\text { Adult }\end{array}$ & $\begin{array}{c}\text { Adult over } \\
\text { Juvenile }\end{array}$ & $\begin{array}{c}\text { Juvenile over } \\
\text { Adult }\end{array}$ & $\begin{array}{c}\text { Juvenile over } \\
\text { Juvenile }\end{array}$ \\
\hline Obs.> Exp. & 3 & 16 & 0 & 5 \\
Obs. = Exp. & 0 & 0 & 0 & 0 \\
Obs. $<$ Exp. & 17 & 4 & 0 & 15 \\
P(sign test, two-tailed) & 0.002 & 0.006 & 0 & 0.022 \\
\hline
\end{tabular}

As shown in Table 3 aggressive interactions occurred in 8 of 15 mixed adult and juvenile flocks. Adult over adult $(P=0.002)$ and juvenile over juvenile $(P=0.022)$ were less frequent. Interactions involving adults and juveniles occurred more frequently than expected $(P=0.006)$ and were always of the adult over juvenile type.

\section{Discussion}

The observed frequencies of possible types of aggressive interactions were nonrandom in a mixed adult and juvenile sandpiper population. Dominance in aggressive interactions was age-related in that there was a higher than expected frequency of adult over juvenile interactions. In all interactions involving adults and juveniles, juveniles always moved away from the site of encounter. Similar behaviour was observed by Ridpath (1972) in the Tasmanian native hen Tribonyx morteri where conflicts between adult and juveniles were more frequent than would be expected if conflicts were independent of age. The conflicts were always initiated and won by adults.
The fact that lower than expected frequency of adult over adult and juvenile over juvenile interactions occurred suggested that possibility that adults were selectively aggressive towards juveniles or that juveniles sandpipers were somehow inept at avoiding adults.

There was the possibility that juvenile sandpipers may have responded inappropriately to messages conveyed by adults. Postural display, especially the tail-depressed posture, by adult sandpipers may mean that they were likely to respond aggressively to any bird if approached within a certain distance. This information may be misinterpreted by a juvenile sandpiper or responded to ambivalently to the extent that the juvenile may approach an adult close enough to elicit aggression. The unexpectedly high frequency of adult over juvenile aggressive interactions suggested that juveniles commonly misinterpret or responded ambivalently to such messages.

\section{Acknowledgement}

The authors gratefully acknowledge the assistance rendered by Mr. K. O. Hamzaat in the collection of some of the data used in this work. 


\section{REFERENCES}

Akinpelu, A.I., 2001. Growth and causes of mortality in three species of Estrildid Birds in Ile-Ife, Nigeria. Bioscience Research Communications 13(5), 477487.

Ashmole, N.P., 1963. Regulation of numbers of tropical oceanic birds. Ibis 103b, 458-473.

Brase, C.H. and Brase, C.P., 1987. Understandable Statistics (third edition). D.C. Health and Company, Lexington, Massachusetts. 592pp.

Komolafe, O.O., 1985., The biology of the cichlid fish Tilapia zillii (Gervais) in Opa reservoir, University of Ife, Ile-Ife, Nigeria. Unpublished M.Sc. Thesis of the University of Ife, Nigeria.
Lack, D., 1954. The Natural Regulation of Animal Numbers. Oxford, Clarendon Press, Oxford University, U.K.

Lack, D., 1966. Population Studies of Birds. Clarendon Press, U.K.

Orians, G.H., 1969. Age and hunting success in the brown pelican. Animal Behaviour 17, 316-319.

Recher, H.F. and Recher, J.A., 1969. Comparative foraging behaviour of adult and immature little blue herons (Florida caerulea). Animal Behaviour 17, 320-322.

Ridpath, M.G., 1972. The Tasmanian native hen, Tribonyz morterii. Part 2: The individual, the group and the population. CSIRO Wildlife Research 17, 53-90. 